\title{
The Role of Public Administration in the Elimination of Inequality
}

\author{
Katie Schuldiner \\ Florida International University, Miami \\ Jean-Claude Garcia-Zamor (Corresponding author) \\ Florida International University, Miami \\ Email: garciazamor@hotmail.com
}

Received: May 15, 2016 Accepted: June 02, 2016 Published: June 22, 2016

doi:10.5296/jpag.v6i2.9578 URL: http://dx.doi.org/10.5296/jpag.v6i2.9578

\begin{abstract}
The problem of inequality is now requiring solutions that could not be fully found to solve the problem of poverty. The research question that will be investigated is how to establish a clear distinction between poverty and inequality in public policy debates and how public administrators could formulate and implement policies that will alleviate the current world of inequality. The elimination of poverty will always be difficult because politicians and bureaucrats do not have full control over its geographic and demographic roots. While equality can be understood as parity in the enjoyment of fundamental rights and freedoms, and equality of opportunities with regards to education and work and the fulfillment of one's potential, in policy debates it is the lack of such conditions that is viewed as inequality . Thus, equality is not necessarily viewed as equality of economic conditions but primarily as equality of opportunities for achieving them. This is why it is necessary to refer to the concept of social equity when addressing inequality. The article will review and analyze current literature on poverty, inequality and social equity and will suggest some new approaches for the elimination of inequality. Although the necessary initiatives to achieve such an objective have to come from politics, public administrators will ultimately be the ones to provide a definite plan or procedure to ensure the fulfillment of these political initiatives. The article will address how public policy makers can promote equity and social justice.
\end{abstract}

Keywords: Poverty, Inequality, Social equity, Shrinking middle class 


\section{Introduction}

When discussing current events in public policy, it is nearly impossible to escape the topics of inequality and poverty. Many questions regarding these topics have been left unanswered, such as how public administrators could create better public policies, and also, how to implement these innovative policies that could begin to correct problems regarding these issues. First, it is important to address the meanings of poverty and inequality. The two, though correlated, are still separate concepts. Once the two have been defined, it will then be easier to discuss how there is potential for administrators to start down the road towards equity, both in terms of fiscal solutions, as well as opportunities that may exist for those affected. Though, policies regarding poverty and inequality may never result in a one-hundred percent (amicable) solution, every little bit of help leads to better outcomes in the populations that are affected.

The theory of social equity must also be addressed. This is in order to further grasp the ideas necessary to fix at least some of the detrimental actions, ensuing behaviors, and potentially poor outcomes associated with poverty and overall inequality of certain populations, both within the United States and internationally. This is not a new theoretical proposition or paradigm shift, as the concept of social equity has been apparent in many places throughout history.

Thus, as this article continues, the concepts of poverty and inequality will be defined and described, as will the concept of social equity and its facets (e.g. who is included in the classes encompassed by this definition). Further, hopeful approaches to eliminating some of the burden of these concepts will be given and how they will be applicable to current events. Along with these initiatives, one must address how public policy makers can ameliorate the market failures that can occur because of inequalities. Finally, it must be mentioned that there are potential ways in which policy makers can help to promote equity and social justice.

\section{Poverty}

Poverty has come to mean many different things to many different people in countries all throughout the world. Everyone seems to have their own definition as to what poverty truly is. As an article by Robert Chambers (2006, p. 3) states, "what poverty is taken to mean depends on who asks the question, how it is understood, and who responds." To elaborate, the author describes different facets normally included in various definitions of poverty worldwide. He designates them into five separate clusters. These vary from income-poverty, material lack or want, capability deprivation, a broader, multi-dimensional understanding of deprivation, and the fifth cluster, which the author describes as a multiplicity of the prior clusters' effects, an interaction term.

Another article regarding poverty and its definition, by Peter Townsend (2006), contains other ideas about how poverty can affect individuals. Townsend considers people to be impoverished if they do not have income capacity and if they are disadvantaged from the lack of resources and materials, such as food, services, and other standards afforded to those outside of poverty ranges. This keeps them from productive roles they should be able to play 
in society, and from obligations, interactions, and affiliations that those whom are privileged are accustomed. He also argues poverty is a combination of physical, and, as hinted at previously, social needs.

Standard definitions of poverty usually consist of some arbitrary line of income where, if an individual or family falls below said line, they are impoverished and unable to afford the basic standards and necessities of living a full life. Where does this line get drawn? It is different in all places within all cultures. Even in all these locales, it is a difficult task to name an exact threshold of what constitutes poverty, as it is something that usually must be agreed upon in each specific nation on a national level. This could lead to diverse issues as some places may require more from their inhabitants than in others. Even the United States Federal government has its own definition of poverty, as quoted from Jolliffe $(2004$, p. 6) in an article by Bassett $(2009$, p. 5), poverty is "[a]ny (sic) individual with income less than that deemed sufficient to purchase basic needs of food, shelter, clothing, and other essential goods and services..." This author also reiterates how it is defined differently in all places, even within a nation (as with rural and urban populations).

\section{Inequality}

Next, it is important to comprehend what inequality means. Although it is often linked to poverty, there is a distinct difference between the two. There is an abundance of literature on the two topics with a simple division from each other, which many people, including politicians and policy makers, often neglect to identify. Worstall $(2015$, p. 1) explains this difference between the two topics quite parsimoniously by stating "poverty is when people don't have very much and inequality is when some people have more than others." Poverty is more of an individual concept, applying to a person or a family (but can signify when a country falls into categories of first, second, or third world), whereas inequality addresses distribution of wealth in a society or the differences in access to different services due to the individuality of persons. Emphasis is placed on wealth, because even wealth can have different definitions. As stated previously, poverty is a concept that affects how someone can live a productive life. Inequality is a concept of distribution; some people just come to have more than others. It is in the combination of these two topics that social equity must be addressed.

\section{Social Equity}

The concept of social equity was originally presented to those in the field of Public Administration by H. George Frederickson in the 1960s. It was deemed so important in the field that the National Academy of Public Administration (NAPA) established the Standing Panel on Social Equity in Governance who thus defined social equity as (see Johnson III, 2012, p. 471):

The fair, just and equitable management of all institutions serving the public directly or by contract; the fair, just and equitable distribution of public services and implementation of public policy; and the commitment to promote fairness, justice, and equity in the formation of public policy. 
And, since being introduced, it was further idealized as the third pillar of public administration, behind efficiency and economy (Nijaki, 2015). This signifies social equity's vast importance in the changes that need to and should be made regarding public policy in nations all across the globe, as it is something that does not only affect us here in the United States. It is well-evidenced that no two people were created alike, and though international policies exist to bring balance to the ways in which people are treated, no two people are treated alike.

The definition of social equity must be explained if literature is to help in the discovery and development of new and innovative policies to improve the situation in the nations that deal with poverty and inequality, which unfortunately, exists everywhere in the world. When defining social equity (or inequity), certain groups of individuals labeled protected classes are affected. State and federal laws have determined who fits into these classes as based on their "race, color, national origin, religion, creed, gender (sex), age, disability and veteran's status" (Shippensburg University, n.d., p. 1). These laws include these classes of people "because of certain injustices which have occurred against the members of these groups in the past and present. Social equity is the means used to redress these injuries" (Shippensburg University, n.d., p. 1).

It so happens that those individuals and families that are in the above protected classes tend to be the ones that are most heavily affected by poverty, even if policies and programs have been created to level the injustices faced by these populations. Thus, presidential campaigns, as well as national, state, and even local campaigns of politicians, oftentimes focus on further policies to aid in fighting the social problems of poverty and inequality. Social equity is of utmost importance for these campaigns, then, but politicians seem to blur the meanings of both poverty and inequality when it comes to their debates and/or platforms. Or, even worse regarding these matters, the candidates seem to barely even address it at all, merely brushing over these important topics. This is especially the case when discussing racial inequality, which is also linked to other inequal distributions, not only in such topics like income and wealth, but also in higher education, and other facets of life (Angelo, 2015).

Angelo (2015) also points out an interesting fact while discussing the simple comparison of a white college graduate from a black college graduate; that is, for every one US dollar that a black American college graduate earns, the white American college graduate makes \$1.19. And, he also notes the difference between the median household incomes of both white Americans and black Americans in 2012, which are \$57,000 and \$33,321, respectively. This is a significant difference in earnings amongst households. And, though as public administrators, we seek to ameliorate these disparities, we are still apparently far from creating a balanced scale between races, at least when speaking of income distributions (which is an issue with inequality that could lead to poverty, but again, these topics must be differentiated in discussions on the two).

It is well-known that education is linked to better outcomes in lifestyles, but it is also well-evidenced that access to better schools is a little bit easier for white Americans versus those of other races. Affirmative action has been implemented for decades to level the playing 
field for those Americans who are not white. But, even then, inequalities still exist in obvious forms. Angelo (2015) discusses this in his article. Presidents, candidates, and those throughout administration state objectives to fix problems that exist from social inequities, using affirmative action as a policy tool. Unfortunately, these same people often skirt the topic when votes are needed. They address it when they need to, but only when they need to, as when votes are necessary for election or to get legislation passed. Inequality, poverty, and rights to a good life for all citizens oftentimes come up during campaigning, but when it comes down to it, the issues do not seem to come to fruition.

The question then comes up for which public policy recommendations could be utilized to enhance the rights, the equality (in wealth, education, health, etc.), and even the basic lifestyles of those in the protective classes. Affirmative action had helped out during the Reagan administration and leading up to other campaigns, such as with Presidents Bill Clinton, George W. Bush, and Barack Obama, but it seems that after President Obama's election was celebrated, the issues not only still existed, but now they started to take less precedence, the back-burner, if you will (Angelo, 2015).

As the United States moves into future presidential regimes, it will require even more attention to inequality and poverty for various reasons. Everybody seems to be offended by something or other nowadays, but why? The answer seems to always boil down to inequality and poverty. Of course there are many other explanations, but it seems to play out in the form of black versus white, rich versus poor, urban versus rural, north versus south, etc. Demonstrations, marches, episodes of violence occur because of some disagreement usually pertaining to inequality and/or poverty. All levels of government have a potential hand in creating policies that could help lessen these effects.

Justifications for these policies are simple to make. For example, if public policies that are derived from campaigns could address the concerns of citizens from the listed protected classes, giving them better opportunities for a better sense of well-being, they would not need feel as though their voices are not being heard; they would not feel as if their lives do not matter. These two issues are also important to address globally, not only because of basic human dignities, but because there are many terrorist groups that oftentimes exploit the lives of those that are impoverished and those that are affected by inequalities. It is very unfortunate that these groups of people are exploited by people of power, but it seems to remain a problem throughout history. Therefore, the answer does truly lie in developing public policies that will allow those in the protected classes to gain ground and be treated more equally in societies all around the world. Like mentioned earlier, this will require that nations worldwide work together to develop solutions so that people from all walks of life can approach, and surpass, the line where they come out of poverty, living a much more dignified, productive life.

\section{The Shrinking of the Middle Class in the U.S}

According to a report released recently by the Pew Research Center, a widening wealth gap is moving more households into either higher- or lower-income groups in major metro areas, with fewer remaining in the middle. In nearly one-quarter of metro areas, middle-class adults 
no longer make up a majority, the Pew analysis found. That's up from fewer than 10 percent of metro areas in 2000 (Rugaber, 2016). With the disparities that are growing between socio-economic classes, many U.S. citizens are now feeling that there is a level of inequality of access between the different members of society. An example of this is the housing crash of 2008. For the first time, Americans are no longer expected to have the opportunity to earn enough money to buy a home. The ability to have access to purchase a home in the U.S. has been synonymous with the "American Dream". This was a societal norm that all citizens of the country felt a given right to own a home. Because the right to own a home was being jeopardized by the Great recession of 2008 and the Housing Market Crash of 2008, citizens asked government to intervene. The response was for the government to develop policies that would respond to the needs of its citizenry. The Home Affordable Refinancing Program (HARP) was created. Once Policy and legislation was passed, it became the job of the public administrator to determine how to implement this policy for the benefits of the citizens.

The squeezing of the middle class has animated the 2016 presidential campaign, lifting the insurgent candidacies of Donald Trump and Bernie Sanders. Several surveys show that the majority of Americans would like to see the tax system reformed and the government take more direct action on job creation and poverty reduction, and address inequality in a meaningful way. Each candidate is crafting a message around this, which will keep the issue front and center though the November 2016 elections (Foroohar, 2016). Many experts warn that widening income inequality may slow economic growth and make social mobility more difficult. Research has found that compared with children in more economically mixed communities, children raised in predominantly lower-income neighborhoods are less likely to reach the middle class (Rugaber, 2016). However, the new demographic layout detected by the Pew research is not entirely a new phenomenon. In researching social equity in urban development in a German city, one of the co-authors compared European cities with American ones and pointed out how the U.S. model was constructed with low-income neighborhoods designed for an intended social exclusion (Garcia-Zamor, 2008, pp. 120-122 and Garcia-Zamor, 2014, pp. 59-68).

Pew defines the middle class as households with incomes between two-thirds of the median and twice the median, adjusted for household size and the local cost of living. The median is midway between richest and poorest. It can better capture broad trends than an average, which can be distorted by heavy concentrations at the top or bottom of the income scale. By Pew's definition, a three-person household was middle class in 2014 if its annual income fell between $\$ 42,000$ and $\$ 125,000$. "The shrinking of the American middle class is a pervasive phenomenon," said Rakesh Kochhar, associate research director for Pew and the lead author of the report. "It has increased the polarization in incomes." (Ibid.)

The Pew report studied 229 of the largest U.S. metro areas, which constituted 76 percent of the U.S. population. Overall, cities with the largest middle classes are more likely to be in the Midwest. Those with the biggest low-income populations are more often in the Southwest, particularly near the Mexico border. Metro areas with the highest proportions of upper-income households are more likely to be found in the Northeast or along the West 
Coast.

\section{Policy Recommendations}

Many recommendations have been given throughout history in order to ameliorate the conditions present throughout the world regarding poverty, inequality, and social equity. And, though many policies created by administrators have lessened the gap, some have only been temporary fixes (Hosseini, 2010). In a global economy where things change literally overnight, it is important that these policies continually adjust to these dynamic situations. It is easier said than done to suggest that we as human beings should just treat all people the same, regardless of race, gender, cultural factors, ethnicities, sexual orientation, etc. If this could be done, the field of public administration would not be necessary. Instead, these prejudices have existed for ages. They still exist today, even, and seem to not be disappearing any time soon, if they ever will.

Markets need to be adjusted to include more people that are affected from their social equity labels. The poverty penalty is a very real and consequential thing, harming those that should be protected. I can extend the poverty penalty to other social equity issues, too. Poverty may not be the only reason why individuals face higher costs, prejudice could lead to penalties as well. Sure, income exacerbates the problems, as does the likelihood of increased risks due to the environment in which people live (Nijaki, 2015). Information should be gathered as to what markets are affected by which factors, both qualitatively and quantitatively, leading to indicators addressing poverty, inequality and why market exclusion occurs (Mendoza, 2011). Knowing what causes these problems can help focus more narrowly the public policies necessary to bring those affected up to a more just and fair footing, to approach those that participate in current markets. When dealing with public policy, private companies should not be excluded, as their input could help guide public policy, at least in how information is gathered. Sometimes using private companies as models can help align public organizations with proper goals. Though the two markets function differently, some business models may help. Unfortunately, it takes time to research these potential solutions, time which those in the protected classes may not have.

It is also important to address the geographical factors that exist in increasing the severity of social equity. It is tough to treat all locations the same way since even in their basic geography they differ. All areas have their pros and cons, but it is important that those in the areas that are not as rich (no matter the way that can be defined), be treated the same as to what products and services they are offered. It will take many a great policy to include all people in the same manner. Public administrators have only just begun addressing these problems. There are many areas which can be improved in this matter, especially when discussing policies that provide transparency and accountability, which needs to be much more apparent in legislation.

\section{Conclusion}

In 1998, in one of its Working Papers, the International Monetary Fund (IMF) identified market forces, social norms, ownership of real and human capital, and the role of government 
as the fundamental determinants of inequality. His Chief Tax expert at the time, Vito Tanzi, was the author of the paper. He wrote that the role of government is conditioned by the level of economic and international development. He saw a vicious circle in the sense that when the government is most needed because the market needs corrections, it is often least capable of carrying through the needed corrective functions in an efficient way. In the case of the advanced industrial countries that have efficient markets and larger governments the problem is more acute that in developing countries which are less able to collect taxes to promote their objectives. The governments of these countries find it more difficult to promote policies aimed at reducing inequality except perhaps through expropriations and inefficient regulations. Tanzi stated that even a government highly concerned about inequality should promote, first of all, macroeconomic stability which is a necessary requirement for growth. He emphasized that growth is not only a good provider of jobs, but also a strong provider of public resources necessary to finance social programs that can reduce poverty and inequality (IMF Working Paper, 1998).

Almost two decades after the IMF prescription for the role of government in the elimination of inequality, a poll conducted in 2016 by the Harvard Institute of politics found that only 19\% of Americans ages 18 to 29 identified themselves as "capitalists." In the richest and most market-oriented country in the world, only $42 \%$ of that group said that they "supported capitalism." The numbers were higher among older people; still, only $26 \%$ considered themselves capitalists. A little over half supported the system as a whole (Foroohar, 2016). This poll may represent the perception that the current set of policies does not addressed the inequality that prevails in the U.S.

With the advent of new reforms in Public Administration, the environment in which public administrators have to work in has changed drastically in recent years. Public administrators are called on to do more with less. Not only is it necessary for public administrators to excel in their traditional areas of expertise, they are now called upon to master new sets of skills where they are able to promote cooperation among the many new players present in the delivery of public policy to society. It is the job of the public administrator to measure the disparities that are being created among its socio-economic classes and take corrective actions, while following the guidelines that are set forth by the initiatives of the elected officials of the government.

As previously mentioned, once government officials have decided on which types of policies to use, it is the public administrator who is tasked with turning these grand lofty ideologies into concrete actions that can be implemented. The role of public administrators in the elimination of inequality is manifold. It is the public administrator who has to interpret policies, create rules and regulations, develop procedures, implement the programs and services that are created to carry out these policies, develop indicators to measure the program's outputs and outcomes as well as evaluate programs in order to determine if the actions taken actually did what they were supposed to do. All of this is done so that all members of society can be afforded equal opportunities and access to services, including opportunities to education, health, finances, work, general security and ability to fulfill one's potential. 


\section{Macrothink}

\section{References}

Angelo, N. (2015). What happened to educational equality? Tracing the demise of presidential rhetoric on racial inequality in higher education. New Political Science, 37(2), 224-240. doi:10.1080/07393148.2015.1023490

Bassett, D. L. (2009). Poverty and global ruralism. The Journal of Gender, Race, and Justice, $13(1), 1-25$.

Chambers, R. (2006). What is poverty? Concepts and measures. International Poverty Centre. Brasilia DF, Brazil: United Nations Development Programme - International Poverty Centre. Retrieved January 28, 2016, from http://www.ipc-undp.org/pub/IPCPovertyInFocus9.pdf

Foroohar, R. (2016). Capitalism. The markets are choking our economy. How to save it. In Time, May23, pp. 26-32.

Garcia-Zamor, J.C. (2008). The Leipzig Model: Myth or Reality. A Study of City Management in the former East Germany. Lanham, Maryland: University Press of America.

Garcia-Zamor, J.C. (2014). Strategies for Urban Development in Leipzig, Germany. Harmonizing Planning and Equity. New York: Springer.

Hosseini, H. (2010). Making the unequal global economic structure more just: Going beyond welfare economics, utilitarianism and Rawlsian ethical theories. Humanomics, 26(3), 200-211. doi:10.1108/08288661011074963

IMF Working Paper. (1998). Fundamental Determinants of Inequality and the Role of

Government. Prepared by Vito Tanzi. Washington, D.C.: International Monetary Fund.

Johnson III, R. G. (2012). Promoting social equity in public administration: A much needed topic in the twenty-first century. Public Administration Review, 72(3), 471-473. doi:10.111/j.1540-6210.2012.02583.x

Jolliffe, D. (2004). Rural development research report no. 100. U.S. Department of Agriculture, Economic Research Service. Retrieved from http://www.ers.usda.gov/publications/rdrr100/rdrr100.pdf

Mendoza, R. U. (2011). Why do the poor pay more? Exploring the poverty penalty concept. Journal of International Development, 23(1), 1-28. doi:10.1002/jid.1504

Nijaki, L. K. (2015). Justifying and juxtaposing environmental justice and sustainaility: towards an inter-generational and intra-generational analysis of environmental equity in public administration. Public Administration Quarterly, 39(1), 85-116.

Rugaber, C. (2016). Middle class shrinks in 9 of 10 US cities as income fall. In The Miami Herald, Friday May 13, p. 8A 


\section{Macrothink}

Journal of Public Administration and Governance ISSN 2161-7104 2016, Vol. 6, No. 2

Shippensburg University. (n.d.). What is Social Equity? Retrieved November 2015, from Shippensburg University Web site: http://www.ship.edu/Social_Equity/What_is_Social_Equity_/

Townsend, P. (2006). What is poverty? Concepts and measures. International Poverty Centre. Brasilia DF, Brazil: United Nations Development Programme - International Poverty Centre. Retrieved January 28, 2016, from http://www.ipc-undp.org/pub/IPCPovertyInFocus9.pdf

Worstall, T. (2015, March 19). Poverty and inequality are not the same thing so let's try not to confuse them. Retrieved from Forbes - Economics \& Finance Web site: http://www.forbes.com/sites/timworstall/2015/03/19/poverty-and-inequality-are-not-the-same -thing-so-lets-try-not-to-confuse-them/\#693c256631b0

\section{Copyright Disclaimer}

Copyright for this article is retained by the author(s), with first publication rights granted to the journal.

This is an open-access article distributed under the terms and conditions of the Creative Commons Attribution license (http://creativecommons.org/licenses/by/3.0/). 